\title{
Widespread implementation of controlled upwelling in the North Pacific Subtropical Gyre would counteract diazotrophic $\mathrm{N}_{2}$ fixation
}

\author{
Katja Fennel* \\ Department of Oceanography, Dalhousie University, Halifax, Nova Scotia, Canada
}

\begin{abstract}
Karl \& Letelier (2008; Mar Ecol Prog Ser 364:257-268) examined the stimulation of diazotrophic $\mathrm{N}_{2}$ fixation by controlled upwelling of deep-water nutrients as a potential carbon sequestration strategy in low-nutrient, low-chlorophyll regions such as the North Pacific Subtropical Gyre. They did not examine the effect of buoyancy on vertical stratification. Since seawater upwelled from depth is colder and saltier, and therefore denser than surface water, it would have to be diluted sufficiently to prevent its convective sinking. This dilution would lead to a decrease in vertical stratification, which could counteract $\mathrm{N}_{2}$ fixation, as diazotrophs bloom only under well-stratified conditions. A back-of-the-envelope calculation of the effect of large-scale controlled upwelling on upper ocean stratification shows that controlled upwelling is unlikely to scale up and serve as a climate stabilization wedge as defined by Pacala \& Socolow (2004; Science 305:968-972), i.e. it would not sequester 1 Gt $\mathrm{C} \mathrm{yr}^{-1}$ over $30 \mathrm{yr}$.
\end{abstract}

KEY WORDS: Carbon sequestration - Nitrogen fixation - LNLC - Mixed-layer depth · NSPG · Controlled upwelling $\cdot$ Climate stabilisation wedge

\section{INTRODUCTION}

Karl \& Letelier (2008) examined controlled upwelling of deep-water nutrients as a potential carbon sequestration strategy for low-nutrient, low-chlorophyll (LNLC) regions such as the North Pacific Subtropical Gyre (NPSG). They hypothesized that the replacement of surface water with water from depth containing excess $\mathrm{P}$ and Fe relative to fixed N (according to Redfield stoichiometry) could stimulate biological fixation of $\mathrm{N}_{2}$ by diazotrophs, after an initial depletion of nitrate and other bio-available forms of $\mathrm{N}$ has occurred. The portion of production and export based on the newly fixed $\mathrm{N}$ would represent a net uptake of atmospheric $\mathrm{C}$.

The idea of controlled upwelling of nutrients with excess $\mathrm{P}$ and $\mathrm{Fe}$ is similar to ocean fertilization strategies where $\mathrm{Fe}$ and/or $\mathrm{P}$ are added to tropical and subtropical oceans with the expectation that biological $\mathrm{N}_{2}$ fixation will provide the $\mathrm{N}$ necessary to support photoautotrophic growth. However, controlled upwelling differs in 2 important aspects: (1) the upwelled seawater also contains inorganic carbon, which must be taken into account when the net $C$ balance is assessed; (2) seawater upwelled from depth is denser than surface water and would have to be diluted to prevent its convective sinking. While Karl \& Letelier (2008) assessed the first issue of inorganic carbon upwelling in their budget calculation, they did not consider the buoyancy effect. $\mathrm{N}_{2}$ fixation requires relatively high water temperatures and a well-stratified upper water column (Karl et al. 1995, 1997, Capone et al. 1997, Karl 1999, White et al. 2007), and addition of dense water will decrease vertical stratification. Although the level of stratification that would be necessary for sufficient $\mathrm{N}_{2}$ fixation to occur is not accurately known, it is prudent to assess how controlled upwelling would affect stratification of the upper water 
column. My goal here is to derive a preliminary estimate of how stratification of the upper ocean would be modified by large-scale upwelling. My analysis is similar to that presented by Karl \& Letelier (2008) in using Station ALOHA as a reference point for the NPSG and in using their estimates of net $\mathrm{C}$ sequestration per $\mathrm{m}^{3}$ of upwelled seawater (Karl \& Letelier 2008, their Table 1). A simple calculation, described below, provides an upper limit on the magnitude of $C$ sequestration that could be expected if controlled upwelling were implemented across the NPSG.

\section{METHODS}

In an optimistic scenario, it is assumed that controlled upwelling is implemented over the entire NPSG (an area of $34 \times 10^{6} \mathrm{~km}^{2}$ ) and that the target for $\mathrm{C}$ sequestration is $1 \mathrm{Gt} \mathrm{C} \mathrm{yr}^{-1}\left(8.3 \times 10^{13} \mathrm{~mol} \mathrm{C} \mathrm{yr}^{-1}\right)$. In this case, $2.44 \mathrm{~mol} \mathrm{C}$ has to be taken up from the atmosphere per $\mathrm{m}^{2}$ of surface area per year, i.e. $45 \mathrm{~m}^{3}$ of seawater per $\mathrm{m}^{2}$ of surface area has to be pumped per year if water were upwelled from $400 \mathrm{~m}$ depth (assuming that Station ALOHA conditions apply across the entire NPSG, and using Karl \& Letelier's 2008 estimate of $0.0545 \mathrm{~mol} \mathrm{C}$ sequestered per $\mathrm{m}^{3}$ of seawater upwelled).

In order to assess the utility of controlled upwelling as a strategy for $\mathrm{C}$ sequestration, its widespread implementation must be postulated. Under the scenario of implementation across the NPSG, lateral mixing is neglected and the effect on upper ocean stratification approximated by calculating how the average density profile of a water column of $1 \mathrm{~m}^{2}$ surface area would be affected by upwelling. Under the optimistic assumption that no upwelled water is lost to depths below the euphotic zone by convection, the mixing equation is used to determine the resulting surface stratification. Given a surface mixed layer with thickness $z_{k}$ and volume $V_{\text {mixed, }}$ and given its density $\rho_{k}$ and the density $\rho_{k+1}$ at depth $z_{k+1}$ directly under the mixed layer, the mixing equation is:

$$
x \times \rho_{\text {upw }}+V_{\text {mixed }} \times \rho_{k}=\left(V_{\text {mixed }}+x\right) \times \rho_{k+1}
$$

where $\rho_{\text {upw }}$ is the density of the deep water that is being upwelled, and $x$ is the maximum volume of deep water that can be mixed into the surface layer until stratification will become unstable. Using Eq. (1) the calculation can be carried out as follows:

(1) Computation of the mean of all potential density profiles available for Station ALOHA (CTD data at http://hahana.soest.hawaii.edu) as:

$$
\rho=\left(\rho_{1}, \rho_{2}, \ldots, \rho_{K}\right)^{\mathrm{T}} \text { at depths } z=\left(z_{1}, z_{2}, \ldots, z_{K}\right)^{\mathrm{T}}
$$

which serves as the initial density profile.
(2) Computation of $V_{\text {upw }}$, the volume of seawater that would have to be upwelled in order to obtain a desired sequestration of $\mathrm{C}$.

(3) Starting at the surface $z_{k}(k=1)$, computation of $x$, the volume of seawater that can be mixed into the top layer, according to Eq. (1) as:

$$
x:=V_{\text {mixed }} \times \frac{\rho_{k+1}-\rho_{k}}{\rho_{\text {upw }}-\rho_{k+1}}
$$

and calculation of the updated volume of deep water still to be mixed in, the updated volume of the surface mixed layer, and the updated density profile for $z_{1}, \ldots z_{k}$ according to:

$$
\begin{gathered}
V_{\text {upw }}:=V_{\text {upw }}-x \\
V_{\text {mixed }}:=V_{\text {mixed }}+x \\
\rho_{1, \ldots k}:=\rho_{k+1}
\end{gathered}
$$

(4) Iteration of Step 3 (Eqs. 2 to 5 ) for $k=2, \ldots$ until $V_{\text {upw }}=0$ or, in other words, until all upwelled water has been mixed in. The final vector $\rho_{\text {surf }}=\left(\rho_{1}, \ldots, \rho_{k}\right)^{\mathrm{T}}$ contains the resulting density profile at the surface and $V_{\text {mixed }} / \mathrm{m}^{2}$ is the depth of the homogenized surface layer.

This calculation applies regardless of whether deep water is added at the surface or at the base of the mixed layer. Alteration of stratification at the source depth is not considered here for the sake of simplicity. Matlab code for this calculation is given in Appendix 1 (available at www.int-res.com/articles/suppl/m371 p301_app/).

\section{RESULTS AND DISCUSSION}

Dilution of $45 \mathrm{~m}^{3}$ per $\mathrm{m}^{2}$ per yr of Station ALOHA seawater from $400 \mathrm{~m}$ depth (which would be necessary to sequester $1 \mathrm{Gt} \mathrm{C} \mathrm{yr}^{-1}$ ) results in a calculated density profile that is homogeneous from the surface to a depth of $175 \mathrm{~m}$ (Fig. 1). Most likely such an alteration of surface stratification would impede any diazotrophic growth in addition to disrupting established ecological relationships in the NPSG euphotic zone, where microbes display a fundamental vertical structure (Venrick 1988, 1993, 1999).

Estimates for a range of $\mathrm{C}$ quantities to be sequestered for different depths of source water are

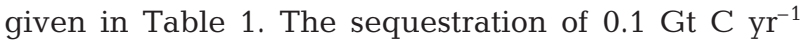
(which according to the above calculation would homogenize the upper $67 \mathrm{~m}$ of the water column for source water from $400 \mathrm{~m}$ ) may be an upper limit for the amount of $\mathrm{C}$ that can possibly be sequestered through controlled upwelling before the alteration of upper ocean stratification counteracts $\mathrm{N}_{2}$ fixation, and thus $\mathrm{C}$ 


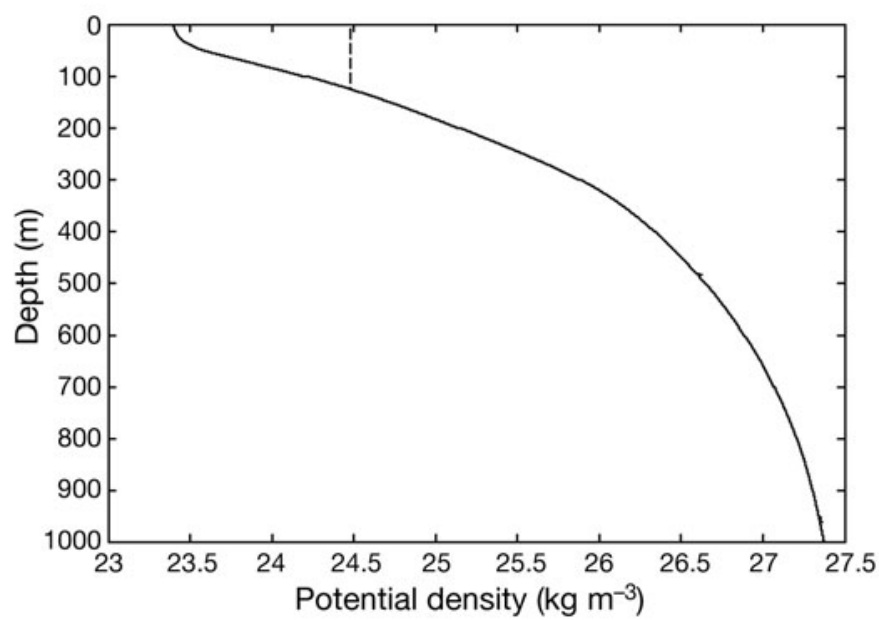

Fig. 1. Initial density profile (solid line) and surface profile that would result (short dashed line) from controlled upwelling of $45 \mathrm{~m}^{3} \mathrm{~m}^{-2} \mathrm{yr}^{-1}$ of water from $400 \mathrm{~m}$ depth across the entire North Pacific Subtropical Gyre. Such upwelling would

be necessary to achieve a carbon sequestration of $1 \mathrm{Gt}$

sequestration. However, it is unlikely that this magnitude of $\mathrm{C}$ sequestration could be sustained and repeated annually, because the erosion of vertical stratification by upwelling in subsequent years would compound over time. In other words, the density profile at the beginning of the second year of large-scale controlled upwelling would be closer to the profile that resulted from upwelling in the first year (e.g. the dashed line in Fig. 1) than the initial profile (solid line in Fig. 1). Continued upwelling in the second year would weaken stratification further.

\section{CONCLUSION}

A climate stabilization wedge as defined by Pacala \& Socolow (2004) requires cutting 1 Gt of C emissions $\mathrm{yr}^{-1}$ for $30 \mathrm{yr}$. Given the considerations presented here, it is unlikely that controlled upwelling can serve as a stabilization wedge. Karl \& Letelier (2008, p. 266) stated that 'well designed and comprehensive nutrient perturbation experiments (...) need to be conducted before diazotroph manipulation can be promoted as a potential climate stabilization wedge'. The considerations presented here show that the effects of water column stratification on the diazotrophs' ability to fix $\mathrm{N}_{2}$ must be included in a comprehensive examination. Furthermore, experimentation with controlled nutrient upwelling on a small scale is of limited use for assessing the effects of a large-scale implementation, because in a small-scale implementation nutrient-rich
Table 1. Depth to which the water column would be homogenized (in $\mathrm{m}$ ) for a certain amount of carbon to be sequestered (rows) by upwelling from different source depths (columns).

Italics: desired sequestration is volumetrically impossible

\begin{tabular}{|lccccccc|}
\hline \multirow{2}{*}{$\begin{array}{l}\text { C } \\
\text { (Gt) }\end{array}$} & 100 & 200 & 300 & 400 & 500 & 750 & 1000 \\
\hline 0.01 & 35.8 & 81.3 & 38.8 & 36.5 & 30.2 & 30.2 & 32.3 \\
0.05 & 59.2 & 165.8 & 59.9 & 54.4 & 45.1 & 44.9 & 49.3 \\
0.10 & 77.1 & 252.6 & 73.7 & 67.0 & 54.1 & 53.8 & 58.3 \\
0.50 & 161.1 & 805.9 & 145.9 & 123.6 & 90.7 & 89.0 & 99.2 \\
1.00 & 251.6 & 1446.6 & 215.6 & 174.6 & 120.7 & 120.1 & 133.4 \\
\end{tabular}

upwelled water will be subject to horizontal mixing, and the effects on vertical stratification will thus be fundamentally different to the scenario of large-scale implementation.

Acknowledgements. I thank Jann Paul Mattern for checking calculations and code, and John Cullen, Robert Moore and Wolfgang Fennel for commenting on an earlier draft of this manuscript. I was supported by the NSERC Discovery Program and the Canada Research Chairs Program while working on this contribution.

\section{LITERATURE CITED}

Capone DG, Zehr JP, Paerl HW, Bergman B, Carpenter EJ (1997) Trichodesmium, a globally significant marine cyanobacterium. Science 276:1221-1229

Karl DM (1999) A sea of change: biogeochemical variability in the North Pacific Subtropical Gyre. Ecosystems 2:181-214

Karl DM, Letelier RM (2008) Nitrogen fixation-enhanced carbon sequestration in low nitrate, low chlorophyll seascapes. Mar Ecol Prog Ser 364:257-268

Karl DM, Letelier RM, Hebel D, Tupas L, Dore J, Christian J, Winn C (1995) Ecosystem changes in the North Pacific Subtropical Gyre attributed to the 1991-92 El Niño. Nature 373:230-234

Karl DM, Letelier RM, Tupas L, Dore J, Christian J, Hebel D (1997) The role of nitrogen fixation in biogeochemical cycling in the subtropical North Pacific Ocean. Nature 388:533-538

> Pacala S, Socolow R (2004) Stabilization wedges: solving the climate problem for the next 50 years with current technologies. Science 305:968-972

Venrick EL (1988) The vertical distributions of chlorophyll and phytoplankton species in the North Pacific central environment. J Plankton Res 10:987-998

Venrick EL (1993) Phytoplankton seasonality in the central North Pacific: the endless summer reconsidered. Limnol Oceanogr 38:1135-1149

Venrick E (1999) Phytoplankton species structure in the central North Pacific 1973-1996: variability and persistence. J Plankton Res 21:1029-1042

White AE, Spitz YH, Letelier RM (2007) What factors are driving summer phytoplankton blooms in the North Pacific Subtropical Gyre? J Geophys Res 112:C12006 